Journal of Bangladesh Academy of Sciences, Vol. 35, No. 2, 187-195, 2011

\title{
CORRELATION BETWEEN STRUCTURE AND THE MAGNETIC PROPERTIES OF AMORPHOUS AND NANOCRYSTALLINE $\mathrm{Fe}_{74} \mathrm{Cu}_{0.5} \mathrm{Nb}_{3} \mathrm{Si}_{13.5} \mathrm{~B}_{9}$ ALLOYS
}

\author{
SIBA P. MONDAL ${ }^{1}$, KAZI HANIUM MARIA ${ }^{* 2}$, S.S. SIKDER ${ }^{1}$, SHIREEN AKHTER ${ }^{3}$, \\ M.A. HAKIM ${ }^{3}$ AND SHAMIMA CHOUDHURY ${ }^{2}$ \\ Department of Physics, Khulna University of Engineering \& Technology, Khulna-9203, \\ Bangladesh
}

\begin{abstract}
Structural and magnetic measurements have been performed on the FINEMET type of ribbons with nominal composition of $\mathrm{Fe}_{74} \mathrm{Cu}_{0.5} \mathrm{Nb}_{3} \mathrm{Si}_{135} \mathrm{~B}_{9}$ synthesized by rapid solidification technique. The crystallization behavior and the nanocrystal formation have been studied by differential thermal analysis (DTA) and X-ray diffraction (XRD). The crystallization onset temperatures determined by XRD are in good agreement with DTA results. Magnetic permeability and magnetization measurements have been carried out using inductance analyzer and vibrating sample magnetometer (VSM). Magnetic permeability sensitively depends on the annealing temperature which increases sharply with the increase of annealing temperature. Maximum permeability corresponding to optimum annealing temperature $\left(T_{a}\right)$ was observed at $T_{a}=575^{\circ} \mathrm{C}$. Saturation magnetization, $\mathrm{M}_{\mathrm{s}}$, increases with $\mathrm{T}_{\mathrm{a}}$ for the sample and finally decreases for annealing at a temperature much higher than peak crystallization temperature. The results show that the amounts of $\mathrm{Cu}$ and $\mathrm{Nb}$ are very important for the soft magnetic properties of FINEMET alloys.
\end{abstract}

Key words: FINEMET, XRD, Grain size, Permeability, Saturation, Magnetization

\section{INTRODUCTION}

Over the past several decades, amorphous and more recently nanocrystalline materials have been investigated for applications in magnetic devices requiring magnetically soft materials such as transformers, inductive devices, etc. Most recently, research interest in nanocrystalline soft magnetic alloys has dramatically increased. The benefits found in the nanocrystalline alloys stem from their chemical and structural variations on a nanoscale which are important for developing optimal magnetic properties. Amorphous soft magnetic alloys are now well accepted as mature materials. The term "Nanocrystalline alloy" will be used for those alloys that have a majority of grain diameters in the typical range from $\approx 1-50 \mathrm{~nm}$. This term will include alloys made by rapid solidification, deposition techniques and solid state reactions, where the initial material may be in the amorphous state and subsequently crystallized. Nanocrystalline

*Corresponding author :<kazimaria@univdhaka.edu>.

${ }^{2}$ Department of Physics, University of Dhaka, Dhaka -1000, Bangladesh

${ }^{3}$ Materials Science Division, Atomic Energy Centre, Dhaka - 1000, Bangladesh 
soft magnetic materials were first reported in 1988 by Yoshizawa et al. (1988), Yoshizawa and Yamachi (1990), Noh et al. (1990) through controlled crystallization of Fe-Si-B amorphous alloys with the addition of copper $(\mathrm{Cu})$ and niobium $(\mathrm{Nb})$ which are known as FINEMET. The magnetic softness of FINEMET alloy mainly arises from the depression of ultrafine grains in an amorphous matrix which reduces the effective magnetic anisotropy and magnetostriction. This indicates that the exchange interaction between nanocrystalline and amorphous phases plays an important role in achieving good soft magnetic properties (Bigot et al. 1994, Manjura Hoque and Hakim 2007). The formation of these nanocrystalline structures is ascribed to the combined addition of $\mathrm{Cu}$ and $\mathrm{Nb}$, which are not soluble in $\alpha-\mathrm{Fe}$. Hereby $\mathrm{Cu}$ is thought to increase the nucleation of $\alpha-\mathrm{Fe}$ grains, whereas $\mathrm{Nb}$ hinders its growth rate (Yoshizawa and Yamachi 1991).

The aim of the present study was to observe structure and measure magnetic properties of $\mathrm{Fe}_{74} \mathrm{Cu}_{0.5} \mathrm{Nb}_{3} \mathrm{Si}_{13.5} \mathrm{~B}_{9}$ and find the correlation between them. Frequency dependence of permeability has been measured in the amorphous and nanocrystalline state with different volume fraction of amorphous and nanocrystalline phase.

\section{MATERIALS AND METHODS}

Amorphous ribbons with the nominal composition $\mathrm{Fe}_{74} \mathrm{Cu}_{0.5} \mathrm{Nb}_{3} \mathrm{Si}_{13.5} \mathrm{~B}_{9}$ were prepared in an arc furnace on a water-cooled copper hearth under an atmosphere of pure Ar. The purity of the constituent elements were, Fe (99.9\%), Nb (99.9\%), Si (99.9\%), Cu (99.9\%) and B (99.9\%) and were obtained from Johnson Mathey (Alfa Aesar Inc.). Amorphousity of the ribbon and nanocrystalline structure have been observed by X-ray diffraction (Philips (PW 3040) X 'Pert PRO XRD) with $\mathrm{Cu}-\mathrm{K}_{\alpha}$ radiation. Crystallization behavior has been performed using Differential Scanning Calorimetry (2960 SDT, USA). Measurement of frequency dependence of initial permeability has been carried out by laboratory built furnace and Wayne Kerr 3255 B Impedance Analyzer. Temperature dependence of magnetization has been performed using 880 DMS Vibrating Sample Magnetometer, USA.

\section{RESULTS AND DISCUSSION}

Fig. 1 shows DTA profile of as-cast amorphous ribbons with a heating rate of $20^{\circ} \mathrm{C} / \mathrm{min}$ in a nitrogen atmosphere. Two exothermic peaks are distinctly observed which correspond to two different crystallization events at temperatures $T_{x_{1}}$ and $T_{x_{2}}$, respectively. The soft magnetic properties correspond to the primary crystallization $\left(T_{x_{1}}\right)$ of $\alpha$-Fe ( $\mathrm{Si}$ ) phase. Secondary crystallization $\left(T_{x_{2}}\right)$ corresponds to Fe-B phase which causes magnetic hardening of the nanocrystalline alloy. The crystallization onset temperatures $\left(T_{x_{1}}\right.$ and $\left.T_{x_{2}}\right)$ and peak temperatures $\left(T_{p_{1}}\right.$ and $\left.T_{p_{2}}\right)$ display exothermic peak, i.e. release of heat during the crystallization of $\mathrm{Fe}(\mathrm{Si})$ and $\mathrm{Fe}-\mathrm{B}$ phases.

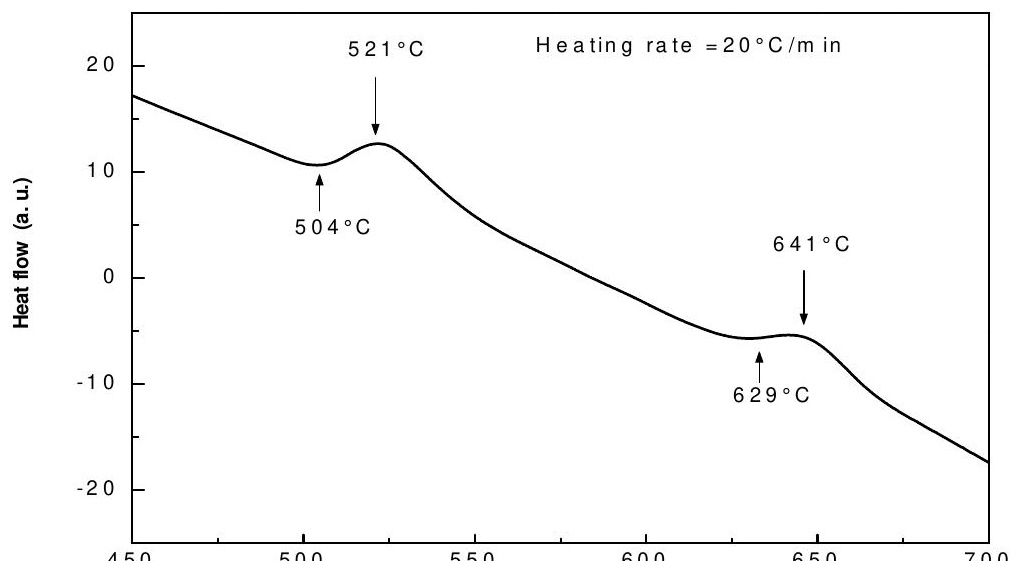


Fig. 1. DTA trace of the as-cast amorphous ribbon with composition $\mathrm{Fe}_{74} \mathrm{Cu}_{0.5} \mathrm{Nb}_{3}$ $\mathrm{Si}_{13.5} \mathrm{~B}_{9}$ alloy with continuous heating.

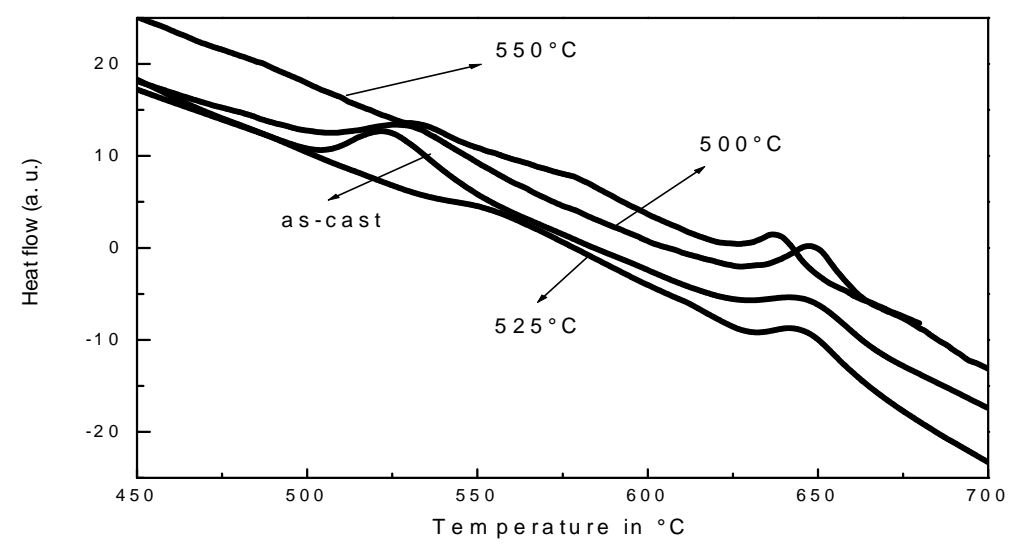

Fig. 2. Effects on DTA traces of as-cast and different annealing temperature on the nanocrystalline amorphous ribbon with composition $\mathrm{Fe}_{74} \mathrm{Cu}_{0.5} \mathrm{Nb}_{3} \mathrm{Si}_{13.5} \mathrm{~B}_{9}$.

The area under the first peak of DTA curve corresponds to the crystallization enthalpy, $\Delta \mathrm{H}$ of $\mathrm{Fe}(\mathrm{Si})$ from which the volume fraction of crystallization $\left(\mathrm{X}_{\mathrm{f}}\right)$ can be estimated according to the formula,

$$
X_{f}=\frac{\Delta H_{a}-\Delta H_{t}}{\Delta H_{a}},
$$

where $\Delta \mathrm{H}_{\mathrm{a}}$ and $\Delta \mathrm{H}_{\mathrm{t}}$ are the crystallization enthalpy of the as-cast alloy and that of the alloy annealed for a time $\mathrm{t}$, respectively. Fig. 2 shows DTA profiles of $\mathrm{Fe}_{74} \mathrm{Cu}_{0.5}$ $\mathrm{Nb}_{3} \mathrm{Si}_{13.5} \mathrm{~B}_{9}$ alloy in the as cast state and annealed at different temperatures for $30 \mathrm{~min}$. From the DTA scan, it is observed that the as-cast and annealed samples at $\mathrm{T}_{\mathrm{a}}=500^{\circ} \mathrm{C}$ do not show any significant change of area under the $1^{\text {st }}$ peak corresponding to the crystallization enthalpy, $\Delta \mathrm{H}$ of $\mathrm{Fe}(\mathrm{Si})$. This means that at $\mathrm{T}_{\mathrm{a}}=500^{\circ} \mathrm{C}$, no crystallization 
occurred which is quite obvious since $\mathrm{T}_{\mathrm{x}_{1}}=504^{\circ} \mathrm{C}$ for this sample. This demonstrates that even annealing at $\mathrm{T}_{\mathrm{a}}=500^{\circ} \mathrm{C}$, the material still remained amorphous. Therefore crystallization enthalpy $\Delta \mathrm{H}$ (area under the peak) is almost equal to that of its amorphous state. But when annealed at $\mathrm{T}_{\mathrm{a}}=525^{\circ} \mathrm{C}$, there is a broad diffused 1 st peak meaning that substantial amount of primary crystallization, $\mathrm{Fe}(\mathrm{Si})$ has already been completed for 30 minutes at $\mathrm{T}_{\mathrm{a}}=525^{\circ} \mathrm{C}$. For $\mathrm{T}_{\mathrm{a}}=550^{\circ} \mathrm{C}$, 1st DTA peak is almost not visible, i.e. crystallization of $\mathrm{Fe}(\mathrm{Si})$ phase has almost completed. A critical scrutiny of 2 nd peak does not show any significant change. This shows that with increasing annealing temperature $\mathrm{X}_{\mathrm{f}}$ is expected to increase. The effect of annealing temperature $\mathrm{T}_{\mathrm{a}}$ on the secondary crystallization is insignificant since the $T_{a}$ is very low compared to $T_{x_{2}}$ (Herzer 1989).

Table 1. Annealing effects on 1st and 2nd crystallization states of the nanocrystalline amorphous ribbon with composition $\mathrm{Fe}_{74} \mathrm{Cu}_{0.5} \mathrm{Nb}_{3} \mathrm{Si}_{13.5} \mathrm{~B}_{9}$ at constant heating rate $20^{\circ} \mathrm{C} / \mathrm{min}$.

\begin{tabular}{cccccc}
\hline $\begin{array}{c}\text { Annealing } \\
\text { temperature }\end{array}$ & $\begin{array}{c}\text { Onset temp. of } \\
\text { primary } \\
\text { crystallization } \\
\mathrm{T}_{\mathrm{x}_{1}}{ }^{\circ} \mathrm{C}\end{array}$ & $\begin{array}{c}\text { Primary crys. } \\
\text { peak } \\
\text { temperature } \\
\mathrm{T}_{\mathrm{p}_{1}}{ }^{\circ} \mathrm{C}\end{array}$ & $\begin{array}{c}\text { Onset temp. of } \\
\text { secondary } \\
\text { crystallization } \\
\mathrm{T}_{\mathrm{x}_{2}}{ }^{\circ} \mathrm{C}\end{array}$ & $\begin{array}{c}\text { Secondary crys. } \\
\text { peak } \\
\text { temperature } \\
\mathrm{T}_{\mathrm{p}_{2}}{ }^{\circ} \mathrm{C}\end{array}$ & $\begin{array}{c}(\Delta \mathrm{T}) \\
\mathrm{T}_{\mathrm{p}_{2}}-\mathrm{T}_{\mathrm{x}_{1}} \\
\text { in }{ }^{\circ} \mathrm{C}\end{array}$ \\
\hline As-cast & 504 & 521 & 629 & 641 & 120 \\
$500^{\circ} \mathrm{C}$ & 507 & 529 & 629 & 648 & 119 \\
$525^{\circ} \mathrm{C}$ & - & - & 630 & 644 & - \\
$550^{\circ} \mathrm{C}$ & - & - & 625 & 638 & - \\
\hline
\end{tabular}

The results of DTA scan on annealing of sample together with as-cast sample with the parameter such as $T_{x_{1}}, T_{x_{2}}, T_{p_{1}}, T_{p_{2}}$ and $\Delta \mathrm{T}$ are depicted in Table 1 . It is observed from the tables that the $T_{x_{1}}, T_{x_{2}}, T_{p_{1}}, T_{p_{2}}$ as well as the difference between the two crystallization events are almost not affected by annealing, just below the crystallization temperatures. When the samples are annealed above the $T_{p_{1}}$, the primary crystallization as evidenced from their DTA curves are so diffused and smeared that they give signals of nearly completion of the primary crystallization of $\mathrm{Fe}(\mathrm{Si})$ crystallites.

XRD spectra of as-cast and annealed at 475 to $700^{\circ} \mathrm{C}$ for 30 minutes have been presented in Fig. 3. It is noticed that initiation of crystallization only takes place at $\mathrm{T}_{\mathrm{a}}=$ $525^{\circ} \mathrm{C}$. Below this annealing temperature there is no sharp peak to indicate crystallization. The broad diffused peak around (110) plane necessarily signifies the amorphous state of the samples annealed at $\mathrm{T}_{\mathrm{a}}=500^{\circ} \mathrm{C}$ and below. XRD pattern clearly indicates the formation of bcc $\mathrm{Fe}(\mathrm{Si})$ phase above $\mathrm{T}_{\mathrm{a}}=525^{\circ} \mathrm{C}$ with the appearance of (110), (200) and (211) fundamental diffraction peaks. With the increasing of $\mathrm{T}_{\mathrm{a}}$, (110) diffraction peak becomes sharper which means that grains are growing bigger with the increase of annealing temperature. From Fig. 3 it is also observed that just below (110) peak, another diffraction line with small peak at $2 \theta \approx 44^{\circ}$ appeared for the samples 
annealed at $\mathrm{T}_{\mathrm{a}}=650$ and $700^{\circ} \mathrm{C}$. This diffraction line has been matched with $\mathrm{Fe}_{23} \mathrm{~B}_{6}$ phase. Therefore the boride phase for this sample has appeared along with bcc $\mathrm{Fe}(\mathrm{Si})$.

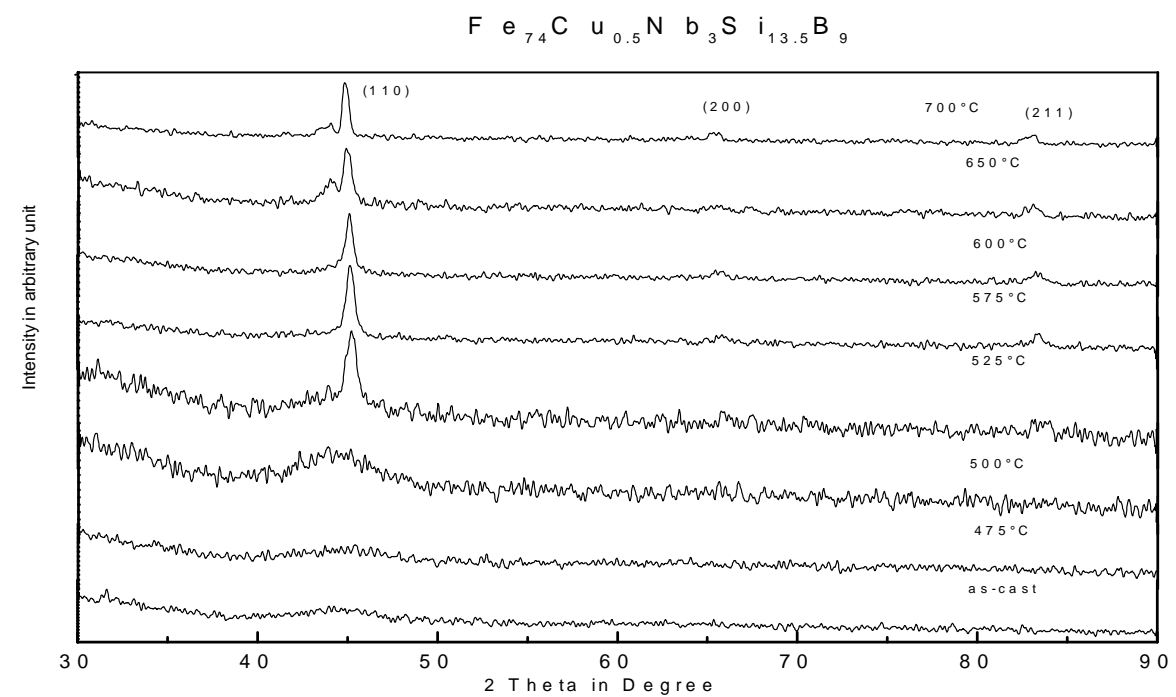

Fig. 3. XRD patterns of $\mathrm{Fe}_{74} \mathrm{Cu}_{0.5} \mathrm{Nb}_{3} \mathrm{Si}_{13.5} \mathrm{~B}_{9}$ alloys for as-cast and heat-treated at 475 to $700^{\circ} \mathrm{C}$ for 30 minutes.

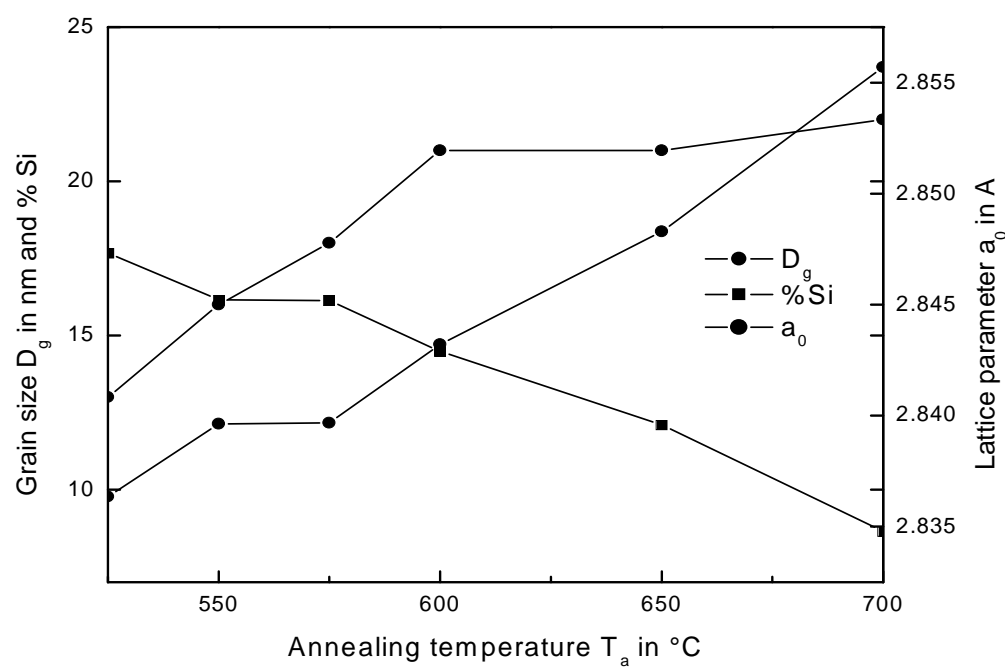

Fig. 4. Variation of $\mathrm{D}_{\mathrm{g}}, \mathrm{a}_{0}$ and Si-content with $\mathrm{T}_{\mathrm{a}}$ for the nanocrystalline amorphous ribbon with composition $\mathrm{Fe}_{74} \mathrm{Cu}_{0.5} \mathrm{Nb}_{3} \mathrm{Si}_{13.5} \mathrm{~B}_{9}$.

Fig. 4 shows the variation of lattice parameter of $\mathrm{Fe}(\mathrm{Si})$ phase, $\mathrm{Si}$-content and grain size of $\alpha-\mathrm{Fe}(\mathrm{Si})$ phase with respect to the annealing temperature of the samples. With the increase of annealing temperature, lattice parameter and grain size increases gradually 
while $\mathrm{Si}$ content of $\mathrm{Fe}(\mathrm{Si})$ phase decreases with $\mathrm{T}_{\mathrm{a}}$. This is contradictory to original Finemet alloy. Such a situation may only be explained by assuming that at high temperature $\left(\mathrm{T}>500^{\circ} \mathrm{C}\right)$ recrystallization of $\mathrm{Fe}(\mathrm{Si})$ grains takes place. Lower $\mathrm{Nb}$ content may also be the reason this deviation. The real cause is not clear and remains still an open question. Enhancement of grain size with annealing temperature corresponds well with the reported results (Rubinstein et al. 2001). The formation of this particular nanostructure is ascribed to the combined effects of $\mathrm{Cu}$ and $\mathrm{Nb}$ and their low solubility in iron. All the results of $\theta$, d-values, FWHM, $\mathrm{a}_{0}, \mathrm{D}_{\mathrm{g}}$ and $\mathrm{Si}$-content from XRD analysis are listed in Table 2.

Table 2. Experimental XRD data of nanocrystalline $\mathrm{Fe}_{74} \mathrm{Cu}_{0.5} \mathrm{Nb}_{3} \mathrm{Si}_{13.5} \mathrm{~B}_{9}$ amorphous ribbon at different annealing temperatures.

\begin{tabular}{ccccccc}
\hline Temperature $\left({ }^{\circ} \mathrm{C}\right)$ & $\theta\left({ }^{\circ}\right)$ & $\mathrm{d}(\AA)$ & FWHM $\left({ }^{\circ}\right)$ & $\mathrm{a}_{0}(\AA)$ & $\mathrm{D}_{\mathrm{g}}(\mathrm{nm})$ & $\mathrm{Si}(\%)$ \\
\hline 525 & 22.604 & 2.005 & 0.70 & 2.8363 & 13 & 17.68 \\
550 & 22.577 & 2.007 & 0.59 & 2.8396 & 16 & 16.15 \\
575 & 22.576 & 2.007 & 0.54 & 2.8396 & 18 & 16.12 \\
600 & 22.547 & 2.010 & 0.46 & 2.8432 & 21 & 14.48 \\
650 & 22.504 & 2.014 & 0.46 & 2.8482 & 21 & 12.10 \\
700 & 22.443 & 2.019 & 0.44 & 2.8556 & 22 & 8.64 \\
\hline
\end{tabular}

Fig. 5 shows the frequency dependence of the real part of the complex initial permeability for as-cast and annealed sample in the temperature range 300 to $600^{\circ} \mathrm{C}$ for 30 minutes at a fixed frequency of $1 \mathrm{kHz}$. The curve reveals the strong dependence of initial permeability on annealing temperature, when annealed at temperature below the onset of crystallization. An increase of $\mu^{\prime}$ with $T_{a}$ from 300 to $475^{\circ} \mathrm{C}$ is observed due to irreversible structural relaxation of the amorphous matrix. At $\mathrm{T}_{\mathrm{a}}=500^{\circ} \mathrm{C}$, the permeability sharply drops to a lower value. This is the temperature around which initiation of crystallization takes place as found by DTA and XRD. The decrease of permeability may be attributed to the new stresses developed in the matrix by the growing crystallites, which act as pinning centers for the domain walls constraining the domain wall mobility as well as weak inter-grain magnetic coupling since the growing crystallites are far apart from each other representing small volume fraction that cannot be exchange coupled and the anisotropy cannot be averaged out (Hakim and Manjura 2004, Maria et al. 2011). Further increase of annealing temperature leads to the increase of permeability due to the increase of volume fraction of $\alpha-\mathrm{Fe}(\mathrm{Si})$ nanograins coupled via exchange interaction resulting in a reduction of anisotropy energy. The trends of increasing low frequency permeability exist up to $575^{\circ} \mathrm{C}$, i.e. maximum permeability corresponding to the best soft magnetic properties is observed at this temperature. A large enhancement of $\mu^{\prime}$ was observed above the annealing temperature of $T_{a}=575^{\circ} \mathrm{C}, \mu^{\prime}$ drops to lower value radically. The probable reason might be the evaluation of boride 
phase having high anisotropy energy as well as large grain size which attains a value of $21 \mathrm{~nm}$ at $\mathrm{T}_{\mathrm{a}}=600^{\circ} \mathrm{C}$. This may leads to the increase of anisotropy energy to a high value, which essentially reduces the local exchange correlation length weakening the intergranular magnetic coupling as a result of which magnetic hardening takes place (Hasiak et al. 2000, Jing et al. 1996). The boride phase has been detected by our XRD experiment above $600^{\circ} \mathrm{C}$.

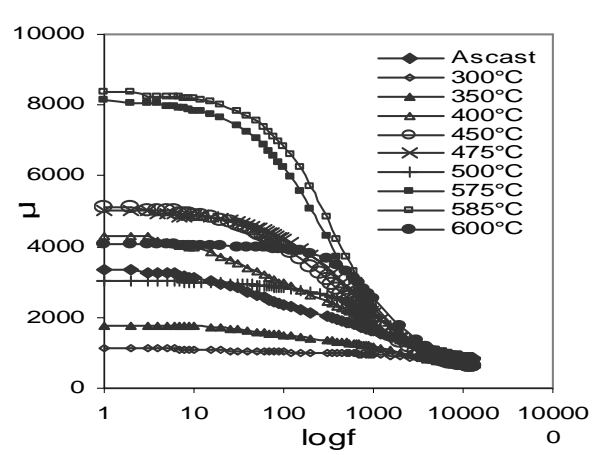

Fig. 5. Frequency dependence of $\mu^{\prime}$ at different $\mathrm{T}$ for 30 minutes of $\mathrm{Fe}_{74} \mathrm{Cu}_{0.5} \mathrm{Nb}_{3} \mathrm{Si}_{13.5} \mathrm{~B}_{9}$ alloy.

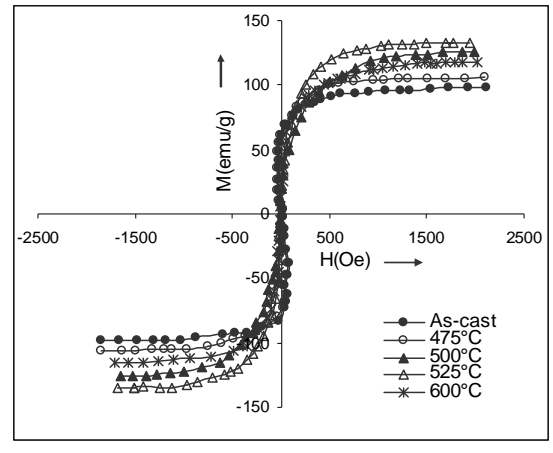

Fig. 6. Specific magnetization versus magnetic field of as-cast and annealed samples of $\mathrm{Fe}_{74}$ $\mathrm{Cu}_{0.5} \mathrm{Nb}_{3} \mathrm{Si}_{13.5} \mathrm{~B}_{9}$ alloy.

Fig. 6 shows the field dependence of specific magnetization for amorphous asquenched and thermally treated samples measured by VSM. It can be seen that with increasing annealing temperature magnetization increases until $\mathrm{T}_{\mathrm{a}}=525^{\circ} \mathrm{C}$. Aranda et al. (1998) have studied the approach to saturation in nanocrystalline FINEMET materials. The magnetization prior to saturation is associated with reversible rotation and has been fitted to the law

$$
M(H)=M_{s}\left[1-\frac{a_{1}}{H}-\frac{a_{2}}{H^{2}}\right]+b H^{1 / 2},
$$

where the term $\frac{a_{2}}{H^{2}}$ was described as being a direct consequence of the random anisotropy model, and attributable to Fe-Si grains. The co-efficient $\mathrm{a}_{2}$ reflects the Herzer's predicted effective magnetic anisotropy of the nanocrystalline material, where as in amorphous alloys it is postulated as being caused by local stress and magneto elastic coupling.

Saturation magnetization $\mathrm{M}_{\mathrm{s}}$, has been observed to increase with the increase of annealing temperature. An increase of $\mathrm{M}_{\mathrm{s}}$ for the annealed samples at 450 to $525^{\circ} \mathrm{C}$ is due to the irreversible structural relaxation, changing the degree of chemical disorder of the amorphous state (Lovas et al. 2000) and enhanced volume fraction of $\mathrm{Fe}(\mathrm{Si}$ ) nanocrystals that are exchange coupled. The saturation magnetizations are shown in Table 3. 
Table 3. The values of saturation magnetization of $\mathrm{Fe}_{74} \mathrm{Cu}_{0.5} \mathrm{Nb}_{3} \mathrm{Si}_{13.5} \mathrm{~B}_{9}$ alloys at different annealing temperature with constant annealing time 30 minutes.

\begin{tabular}{ccc}
\hline Samples & $\begin{array}{c}\text { Annealing temperature, } \\
\mathrm{T}_{\mathrm{a}} \text { in }{ }^{\circ} \mathrm{C}\end{array}$ & $\begin{array}{c}\text { Saturation magnetization, } \\
\mathrm{M}_{\mathrm{s}} \text { in emu } / \mathrm{gm}\end{array}$ \\
\hline & As-cast & 128 \\
$\mathrm{Fe}_{74} \mathrm{Cu}_{0.5} \mathrm{Nb}_{3} \mathrm{Si}_{13.5} \mathrm{~B}_{9}$ & 475 & 133 \\
& 500 & 138 \\
& 525 & 141 \\
& 600 & 124 \\
\hline
\end{tabular}

A rapid decrease in $\mathrm{M}_{\mathrm{s}}$ has been observed with increasing annealing temperature at $600^{\circ} \mathrm{C}$ for $\mathrm{Fe}_{74} \mathrm{Cu}_{0.5} \mathrm{Nb}_{3} \mathrm{Si}_{13.5} \mathrm{~B}_{9}$. The decreasing of $\mathrm{M}_{\mathrm{s}}$ may be connected with the enrichment of the residual amorphous phase with $\mathrm{Nb}$ that weakens the coupling between ferro-magnetic nanograins (Berkowitz et al. 1981). Also the role of Si diffusion into Fe (Si) nanograins and these local environments also may have effect in decreasing $\mathrm{M}_{\mathrm{s}}$. The decrease of $\mathrm{M}_{\mathrm{s}}$ for the sample higher annealing temperature on ordering of $\mathrm{Fe}_{3} \mathrm{Si}$ nanograin can not be ruled out.

\section{CONCLUSION}

Nanocrystalline amorphous ribbons of the Finemet family with nominal composition $\mathrm{Fe}_{74} \mathrm{Cu}_{0.5} \mathrm{Nb}_{3} \mathrm{Si}_{13.5} \mathrm{~B}_{9}$ have been studied to find out the correlation between microstructural features and soft magnetic properties as dependent on various stages of nanocrystallization during the isothermal annealing around the crystallization temperature of their amorphous precursors. DTA reveals the primary, $\mathrm{Fe}(\mathrm{Si})$ and secondary $(\mathrm{Fe}-\mathrm{B})$ crystallization temperatures with the manifestation of two well-defined exothermic peaks. Magnetic initial permeability of nanocrystalline/amorphous ribbon strongly depends on annealing temperature. The improvement in the soft magnetic properties can be ascribed to the much refined grain structure in the range of 10 to $20 \mathrm{~nm}$ obtained at various temperatures during annealing. When alloys were annealed for 30 minutes at various temperatures, the maximum initial permeability $\left(\mu^{\prime}\right)$ were observed at $T_{a}=575^{\circ} \mathrm{C}$. The saturation magnetization for nanocrystalline samples has slightly increased for annealing at temperature around the onset of crystallization. When annealed at higher temperature at which complete crystallization takes place, magnetization decreases again.

\section{ACKNOWLEDGMENTS}

The authors gratefully acknowledge Dr. Dilip Kumar Saha of Material Science Division, Atomic Energy Centre, Dhaka for his help in XRD measurements. REFERENCES

Aranda, G. R., J. Gonzalez, and K. Kulakowski. 1998. Approach to the magnetic Saturation in Nanacrystalline Ferromagnets in the random anisotropy model. J. Appl. Phys. 83: 6341-6344. 
Berkowitz, A. E., J. L. Walter and K. F. Wall. 1981. Magnetic properties of amorphous particles produced by Spark Frosion. Phys. Rev. Lett. 46: 1484-1486.

Bigot, J., N. Lecaude, J. C. Perron, C. Millan, C. Ramiarinjaona and J. F. Rialland. 1994. Influence of Annealing Conditions on Nanocrystalization and Magnetic Properties in $\mathrm{Fe}_{73.5} \mathrm{Cu}_{1} \mathrm{Nb}_{3}$ $\mathrm{Si}_{13.5} \mathrm{~B}_{9}$ alloy. J. Magn. Magn. Mater. 133: 299-303.

Hakim M. A. and S. Manjura Hoque, (2004), "Effect of structural parameters on soft magnetic properties of two phase nanocrystalline alloy of $\mathrm{Fe}_{73.5} \mathrm{Cu}_{1} \mathrm{Ta}_{3} \mathrm{Si}_{13.5} \mathrm{~B}_{9}$ ", J. Magn. Magn. Mater. 284: $395-402$.

Hasiak, M., J. Zbroszczyk, J. Olszewki, W. H. Ciuzynska, B. Wyslocki and A. Blachowicz. 2000. Effect of cooling rate on Magnetic Properties of Amorphous and Nanocrystalline $\mathrm{Fe}_{73.5} \mathrm{Cu}_{1} \mathrm{Nb}_{3}$ $\mathrm{Si}_{15.5} \mathrm{~B}_{7}$ alloy. J. Magn. Magn. Mater. 410: 215-216.

Herzer, G. 1989. Grain Structure and Magnetism of Nanocrystalline Ferromagnets, IEEE Trans. Magn. 25: 3327-3328.

Jing Zhi, Kai-Yuan He, Li-Zhi Cheng, Yu-jan Fu. 1996. Influence of the elements Si/B on the Structure and Magnetic Properties of Nanocrystalline $\left(\mathrm{Fe}, \mathrm{Cu}, \mathrm{Nb}{ }_{77.5} \mathrm{Si}_{\mathrm{x}} \mathrm{B}_{22.5-\mathrm{x}}\right.$ alloys. $J$. Magn. Magn. Mater. 153: 315-317.

Lovas, A. , L. F. Kiss, and I. Balong. 2000. Saturation magnetization and amorphous Curie point changes during the early stage of amorphous-nanocrystalline transformation of a FINEMETtype alloy. J. Magn. Magn. Mater. 463: 215-216.

Manjura, S. Hoque and M. A. Hakim. 2007. Ultra-Soft magnetic properties of devitrified $\mathrm{Fe}_{75.5} \mathrm{Cu}_{0.6} \mathrm{Nb}_{2.4} \mathrm{Si}_{13} \mathrm{~B}_{8.5}$. J. Materials Chemistry and Physics 101: 112-117.

Maria, K. H., Shiba P. Mondal, Shamima Choudhury, S. S. Sikder, M. A. Hakim and D. K. Saha. 2011. Effect of Annealing Temperature on the soft magnetic Properties of $\mathrm{Fe}_{75.5} \mathrm{Cu}_{1} \mathrm{Nb}_{1} \mathrm{Si}_{13.5} \mathrm{~B}_{9}$ Amorphous Alloys. Journal of Emerging Trends in Engineering and Applied Sciences 2(1): 102-108.

Noh, T. H., M. B. Lee, H. J. Kim and I. K. Kang. 1990. Reletionship between crystallization process and magnetic properties of $\mathrm{Fe}-(\mathrm{Cu}-\mathrm{Nb})-\mathrm{Si}-\mathrm{B}$ amorphous alloys. J. Appl. Phys. 67: 5568 .

Rubinstein, M., V. G. Harris and P. Lubitz. 2001. Ferromagnetic resonance innanocrystalline $\mathrm{Fe}_{73.5}$ $\mathrm{Cu}_{1} \mathrm{Nb}_{3} \mathrm{Si}_{13.5} \mathrm{~B}_{9}$ (Finemet). J. Magn. Magn. Mater. 234: 306-308.

Yoshizawa, Y. and K. Yamachi. 1990. Fe-based soft magnetic alloys composed of ultrafine grain structure. Mater. Trans. JIM. 31: 307-308.

Yoshizawa, Y. and K. Yamachi. 1991. Magnetic properties of Fe-Cu-M-Si-B (M = Cr, V, Mo, Nb, Ta, W) alloy. Mater. Sci. Eng. A. 33: 176-179.

Yoshizawa, Y., S. Oguma and K. Yamauchi. 1988. New Fe-Based Soft Magnetic Alloys Composed of Ultra fine Grains Structure. J. Appl. Phys. 64: 6044-6047. 